\title{
The differentiation effect of low-dose cytosine arabinoside is disturbed in PU.1-knockdown K562 cells
}

\author{
HIROKO NAKANO $^{1}$, AKANE YANAGITA ${ }^{1}$ and SHINICHIRO TAKAHASHI ${ }^{1,2}$ \\ ${ }^{1}$ Division of Hematology, Kitasato University School of Allied Health Sciences; ${ }^{2}$ Division of Molecular Hematology, \\ Kitasato University Graduate School of Medical Sciences, Sagamihara, Kanagawa 252-0373, Japan
}

Received March 13, 2014; Accepted March 25, 2014

DOI: $10.3892 /$ br.2014.265

\begin{abstract}
We recently demonstrated by using PU.1-knockdown K562 (K562 PU.1KD) cells stably expressing PU.1 short inhibitory RNAs and PU.1-overexpressing K562 (K562 PU.1OE) cells, that therapeutic concentrations of 5-aza-2'-deoxycytidine (5-azadC) induce erythroid differentiation of these cells and that the PU.1 expression level is closely associated with the differentiating and apoptotic effects of 5-azadC on K562 cells. In this study, we investigated whether the effects of low-dose cytosine arabinoside (Ara-C), which is another erythroid differentiation inducer in K562 cells, is associated with the expression level of PU.1 in these cells. As a result, we demonstrated that the effect of Ara-C on cell viability and differentiation, as determined by the WST- 8 assay and $\beta$-globin mRNA expression analysis, respectively, was suppressed in K562 PU.1KD cells compared to their controls. Collectively, these findings suggest that sufficient expression of PU.1 is indispensable for the erythroid differentiation of K562 cells.
\end{abstract}

\section{Introduction}

PU.1 is a member of the Ezb transformation-specific sequence family of transcription factors and is expressed mainly in granulocytic, monocytic and B lymphoid cells (1). The downregulation of PU.1 was reported to play a role in the pathogenesis of various hematological malignancies, including acute myeloid leukemia (2), multiple myeloma (3) and acute lymphoblastic leukemia (4). Furthermore, several studies indicated that downregulation of PU.1 is required for erythroid terminal differentiation (5).

We recently demonstrated that the effects of the DNA methyltransferase inhibitor 5-aza-2'-deoxycytidine (5-azadC)

Correspondence to: Professor Shinichiro Takahashi, Division of Hematology, Kitasato University School of Allied Health Sciences and Division of Molecular Hematology, Kitasato University Graduate School of Medical Sciences, 1-15-1 Kitasato, Minami-ku, Sagamihara, Kanagawa 252-0373, Japan

E-mail: shin@kitasato-u.ac.jp

Key words: PU.1, erythroid differentiation, cytosine arabinoside, K562 are correlated with PU.1 expression in PU.1-transgenic chronic myeloid leukemia-derived K562 cells (6). We revealed that therapeutic concentrations of 5-azadC induce erythroid differentiation of these cells. PU.1 expression is closely associated with the effect of this agent and sufficient PU.1 levels were shown to accelerate erythroid differentiation and apoptosis induced by 5 -azadC (6).

Several studies indicated that low concentrations of cytosine arabinoside (Ara-C) induce erythroid differentiation of K562 cells $(7,8)$. In this study, we investigated whether the effects of Ara-C are also associated with the expression level of PU.1.

\section{Materials and methods}

Cell culture of PU.1-knockdown K562 (K562 PU.1KD) and PU.1-overexpressing K562 (K562 PU.1OE) cells. K562 PU.1KD and K562 PU.1OE cells were previously established in our laboratory $(9,10)$ and were employed in this study. Specifically, we used 2-10 and 3-10 as K562 PU.1KD cells with vec 5 and vec 6 as their control cells and H8 and A2 as K562 PU.1OE cells with vec 1 and vec 2 as their control cells. The K562 PU.1KD cells were maintained in RPMI-1640 medium (Gibco-BRL, Rockville, MD, USA) containing 10\% heat-inactivated fetal bovine serum (HIFBS) and $1 \mu \mathrm{g} / \mathrm{ml}$ puromycin. The K562 PU.1OE cells were grown in RPMI-1640 containing $10 \%$ HIFBS and $400 \mu \mathrm{g} / \mathrm{ml}$ neomycin. All the cells were cultured under $5 \% \mathrm{CO}_{2}$ at $37^{\circ} \mathrm{C}$ in a humidified atmosphere.

Assessment of cell viability. The proportion of viable cells was determined by a dye reduction assay involving 2-(2-methoxy-4-nitrophenyl)-3-(4-nitrophenyl)-5-(2,4-disulfophenyl)2H-tetrazolium monosodium salt (WST-8; Dojindo, Kunamoto, Japan), which is a modification of the 3-(4,5-dimethylthiazol-2-yl)-2,5-diphenyltetrazolium bromide assay. The effective dose $(E D)_{50}$ values were calculated from the data obtained by the cell growth assays. We selected 7 different Ara-C (Sigma, St. Louis, MO, USA) doses, with the group without Ara-C serving as control, and performed the assays 5 days after addition of Ara-C. The viable cells (\%) were calculated as the ratio of the absorbance $(490 \mathrm{~nm})$ of Ara-C-treated to that of Ara-C-untreated cells in the cell growth assays. The calculated ratios were analyzed using the website http://www. 
A

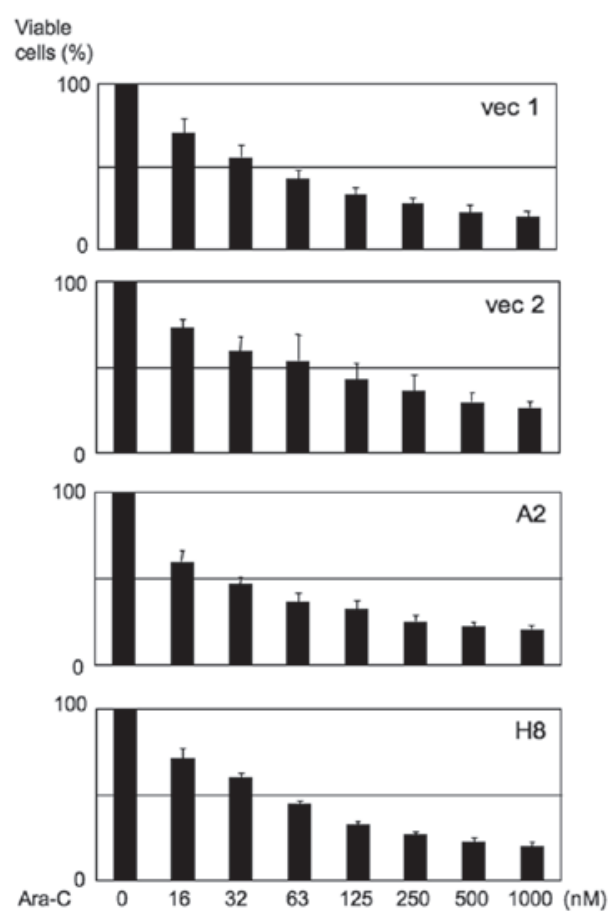

B

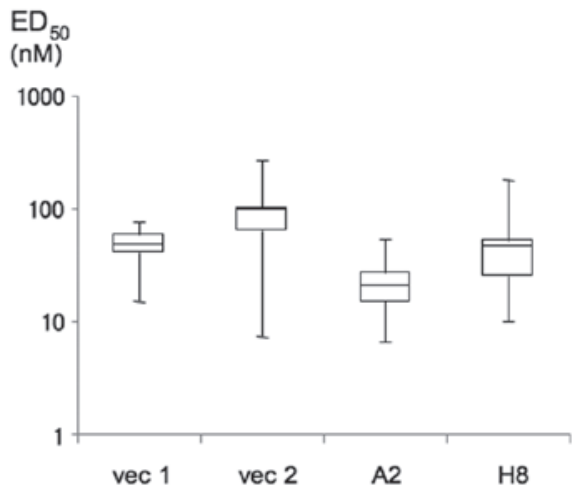

Figure 1. Low-dose cytosine arabinoside (Ara-C) effects on cell viability and effective dose (ED) $)_{50}$ values in PU.1-overexpressing K562 (K562 PU.1OE) cells. (A) Effects of Ara-C on cell viability. The indicated amounts of Ara-C were added to K562 PU.1OE cells (A2 and H8) and their controls (vec 1 and vec 2), incubated for 5 days and the WST-8 assay was performed. The percentage of viable cells (\%) is shown in the y axis. Data were calculated from 5-6 independent experiments and each experiment was performed in triplicate. (B) $\mathrm{ED}_{50}$ values. The $\mathrm{ED}_{50}$ values were calculated as described in Materials and methods. The data are presented as boxplots representing the 25th and 75th percentile, median and 5-95 range.

vector.co.jp/soft/win95/edu/se248471.html and the $\mathrm{ED}_{50}$ values were obtained.

mRNA expression analysis. cDNAs were prepared from cells using reverse transcription (Transcriptor First Strand cDNA synthesis kit; Roche Diagnostics, Mannheim, Germany). Quantitative polymerase chain reaction (qPCR) was performed using QuantiTect SYBR Green PCR reagent (Qiagen, Miami, FL, USA) according to the manufacturer's protocol and using an Opticon Mini Real-Time PCR instrument (Bio-Rad, Hercules, CA, USA) as previously described (11). The primer sequences were as follows: a-globin: forward, 5'-AAGGTCGGCGCGCACGCT-3' and reverse, 5'-CTCAGGTCGAAGTGCGGG-3'; human $\beta$-globin: forward, 5'-CTCATGGCAAGAAAGTGCTCG-3' and reverse, 5'-AATTCTTTGCCAAAGTGATGGG-3'; and GAPDH: forward, 5'-GAAGGTGAAGGTCGGAGT-3' and reverse; 5'-GAAGATGGTGATGGGATTTC-3'. The thermal cycling conditions for $\alpha$-globin were incubation at $95^{\circ} \mathrm{C}$ for $15 \mathrm{~min}$, followed by 35 cycles at $95^{\circ} \mathrm{C}$ for $15 \mathrm{sec}$, at $55^{\circ} \mathrm{C}$ for $15 \mathrm{sec}$ and at $72^{\circ} \mathrm{C}$ for $15 \mathrm{sec}$. The thermal cycling conditions for $\beta$-globin and GAPDH were incubation at $95^{\circ} \mathrm{C}$ for $15 \mathrm{~min}$, followed by 35 cycles at $95^{\circ} \mathrm{C}$ for $30 \mathrm{sec}$, at $55^{\circ} \mathrm{C}$ for $30 \mathrm{sec}$ and at $72^{\circ} \mathrm{C}$ for $45 \mathrm{sec}$. The copy number of each sample was calculated as previously described (12).

Statistical analysis. Data are expressed as means \pm standard error of the mean and ${ }^{*} \mathrm{P}<0.05$ was considered to indicate a statistically significant difference, whereas ${ }^{* *} \mathrm{P}<0.01$. Comparison of the means was performed with the Student's t-test (http://www.physics.csbsju.edu) between all the controls and each group of K562 PU.1KD or K562 PU.1OE cells.

\section{Results}

$E D_{50}$ of Ara-C is increased in K562 PU.1KD cells. We first assessed the viability of K562 PU.1OE cells in the presence of various concentrations of Ara-C, as depicted in Fig. 1A. The range of the Ara- $\mathrm{C}$ dose and time of incubation for erythroid differentiation was based on the results published by Sztiller-Sikorska et al (8). Based on the data presented in Fig. 1A, we calculated $\mathrm{ED}_{50}$ from the Ara-C effect on cell viability. As a result, in K562 PU.1OE A2 cells, the $\mathrm{ED}_{50}$ value tended to be decreased (6.55-53.2 nM, median $20.38 \mathrm{nM}$; $\mathrm{P}=0.099)$. However, there was no difference between K562 PU.1OE H8 cells and their controls [H8: 10.1-179.26 nM, median $45.7 \mathrm{nM}$; vec 1 (control): 14.9-76.24 nM, median $47.80 \mathrm{nM}$; vec 2 (control): 7.28-267.17 nM, median $95.3 \mathrm{nM}$ ] (Fig. 1B).

We then assessed cell viability (Fig. $2 \mathrm{~A}$ ) and $\mathrm{ED}_{50}$ value (Fig. 2B) in K562 PU.1KD cells. In contrast to the results of the K562 PU.1OE cells, the $\mathrm{ED}_{50}$ value was distinctly increased in 2-10 cells (62.75-250.59 nM, median $137.16 \mathrm{nM}$; $\mathrm{P}=0.0042)$, which exhibited the lowest PU.1 expression among all cell lines $(9,10)$, compared to their controls (vec 5: 18.53-72.06 nM, median $30.47 \mathrm{nM}$; vec 6: 7.88-28.46 nM, 
A

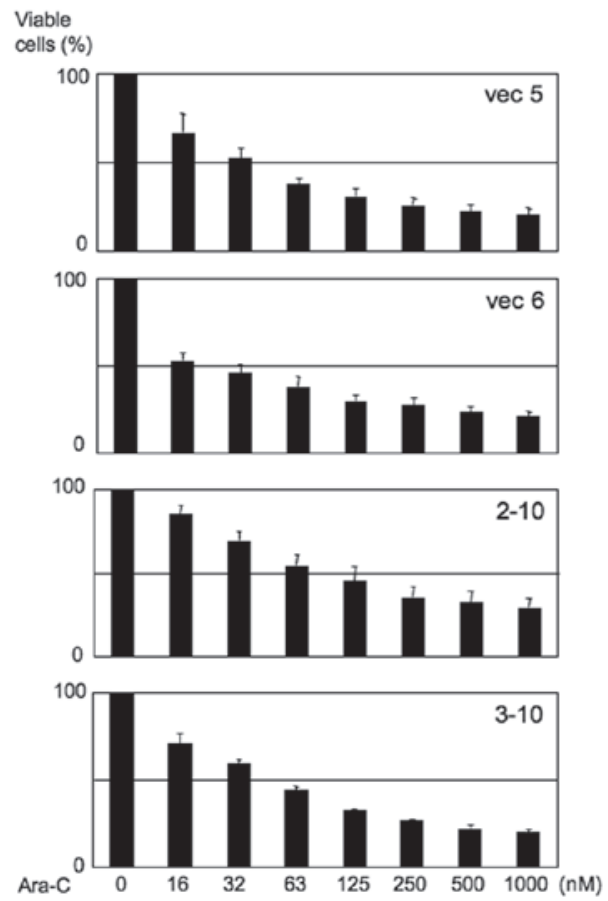

B

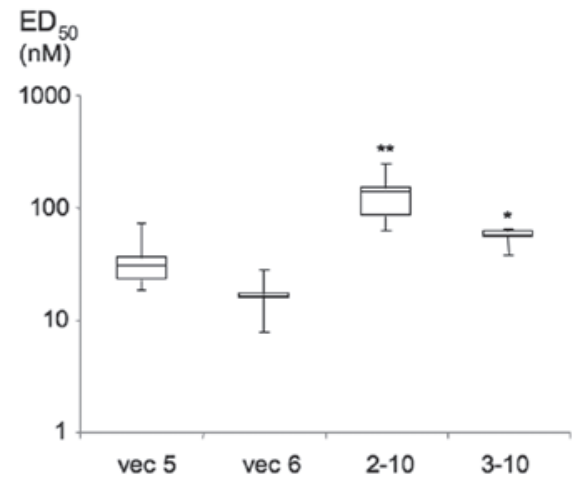

Figure 2. Low-dose cytosine arabinoside (Ara-C) effects on cell viability and effective dose (ED) $)_{50}$ values in PU.1-knockdown K562 (K562 PU.1KD) cells. (A) Effects of Ara-C on cell viability. The indicated amounts of Ara-C were added to K562 PU.1KD cells (2-10 and 3-10) and their controls (vec 5 and vec 6). Of note, 2-10 cells are K562 PU.1KD cells with the lowest PU.1 expression (9,10). Data were calculated from 3-4 independent experiments and each experiment was performed in triplicate. (B) $\mathrm{ED}_{50}$ values. The $\mathrm{ED}_{50}$ values were calculated as described in Materials and methods. Data are presented as boxplots representing the 25 th and 75 th percentile, median and 5-95 range. P-values less than 0.05 were considered significant, denoted by one asterisk, whereas *** means $\mathrm{P}<0.01$.

A

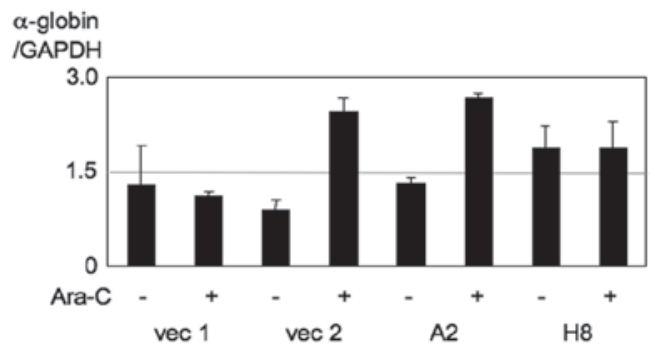

B

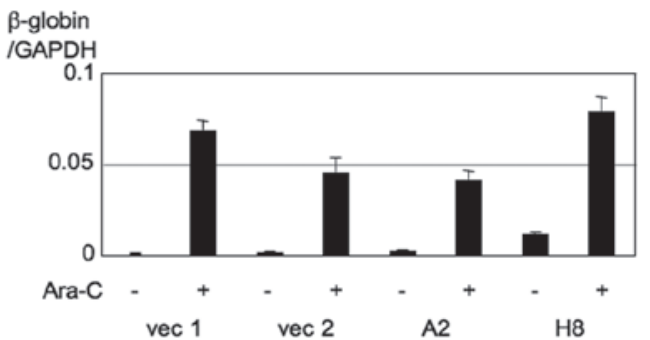

Figure 3. Quantitative polymerase chain reaction (PCR) analyses of (A) $\alpha$-globin and (B) $\beta$-globin using PU.1-overexpressing K562 cells. The $\alpha$-globin and $\beta$-globin gene transcript levels were adjusted by the expression of GAPDH and the relative levels are shown. The data presented were obtained from 3 independent PCR amplifications. Ara-C, cytosine arabinoside.

A

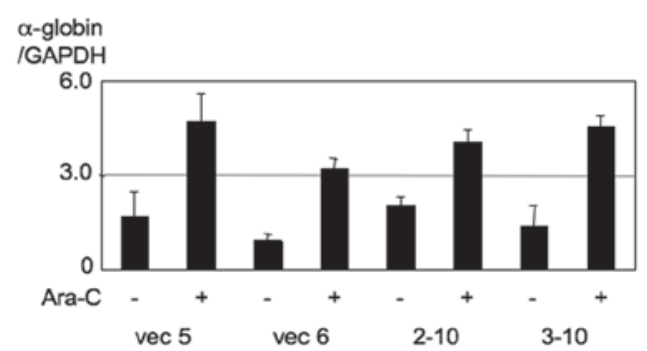

B

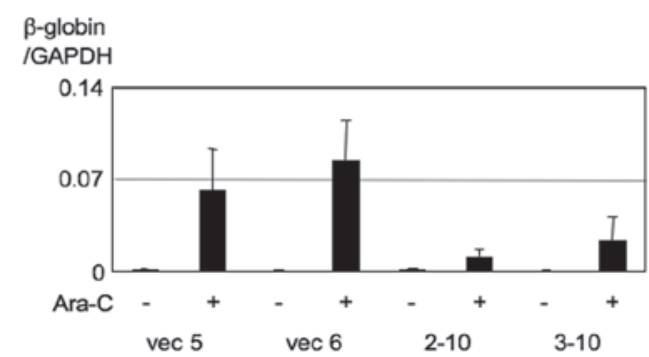

Figure 4. Quantitative polymerase chain reaction (PCR) analyses of (A) $\alpha$-globin and (B) $\beta$-globin using PU.1-knockdown K562 cells. The $\alpha$-globin and $\beta$-globin gene transcript levels were adjusted by the expression of GAPDH and the relative levels are shown. The data presented were obtained from 6 independent PCR amplifications. Ara-C, cytosine arabinoside. 
median $16.17 \mathrm{nM})$. Relatively high $\mathrm{ED}_{50}$ values were also observed in K562 PU.1KD 3-10 cells (37.56-65.02 nM, median $56.93 \mathrm{nM}$; $\mathrm{P}=0.025)$, which exhibited the second lowest expression of PU.1 next to 2-10 cells. Collectively, these findings demonstrated that the Ara- $\mathrm{C}$ effect on cell viability was suppressed in K562 PU.1KD cells.

$\beta$-globin expression is significantly disturbed in $\mathrm{K} 562$ PU.1KD cells following treatment with Ara-C. We then investigated whether the indicated dose of Ara-C leads to the differentiation of K562 cells and whether the effects of $\mathrm{ED}_{50}$ values are associated with the induction of erythroid differentiation genes. For this purpose, we assessed the expression of $\alpha$-globin and $\beta$-globin by qPCR. In K562 PU.1OE cells, the baseline expression of $\alpha$-globin is extremely high $(\alpha$-globin copy number/GAPDH copy number: 1.1-1.8) and moderately affected by the addition of Ara-C (Fig. 3A). By contrast, Ara- $\mathrm{C}$ significantly induces $\beta$-globin expression, suggesting that measuring $\beta$-globin expression may be a good marker to evaluate Ara-C-induced K562 cell differentiation. However, there were no obvious differences between K562 PU.1OE cells and their controls (Fig. 3B). We then investigated these effects using K562 PU.1KD cells. As a result, we observed that $\beta$-globin expression was markedly induced by Ara-C and this induction was significantly disturbed in K562 PU.1KD 2-10 and 3-10 cells (Fig. 4). These findings were consistent with $\mathrm{ED}_{50}$ values, suggesting that the Ara-C effect on cell viability is associated with the effect on erythroid differentiation of K562 cells and these effects are disturbed by the lack of expression of PU.1.

\section{Discussion}

It was previously reported that constitutive upregulation of PU.1 is considered to be the main cause for the inhibition in the differentiation process of murine erythroleukemia (MEL) cells and PU.1 downregulation is required for terminal erythroid differentiation (5,13-15). However, several studies indicated a requirement for PU.1 expression for erythroid differentiation $(6,16,17)$. Back et al $(16)$ demonstrated a requirement of PU.1 expression in erythroid differentiation. The authors of that study produced a line of PU.1-deficient mice carrying a green fluorescent protein reporter at this locus and revealed that PU.1-deficient fetal erythroid progenitors lose their self-renewal capacity and undergo proliferation arrest, premature differentiation and apoptosis (16). Wontakal et al (17) demonstrated that PU.1 regulates an extensive network of genes that constitute major pathways for controlling the growth and survival of immature myeloid cells. That study further revealed that fetal liver erythroid progenitors, the earliest erythroid-committed cells, are significantly reduced in mice with low PU.1 expression in vivo (17). The findings of these studies, including those of the present study, suggest that sufficient expression of PU.1 is indispensable for erythroid differentiation. As previously described (18), one possible explanation for this discrepancy between studies employing MEL cells, is that K562 cells express the endogenous $\varepsilon$-globin and $\gamma$-globin genes, but not the adult stage-specific $\beta$-globin gene and, therefore, have been considered as a model for embryonic-fetal stages of erythroid development $(19,20)$. Wontakal's and Back's studies employed fetal liver erythroid progenitors from mice, which are used for analyzing the embryonic-fetal stages, whereas MEL cells are considered to be a model for fetal-adult development (20), which are employed in the majority of the previous studies analyzing the functions of PU.1 during erythroid differentiation $(6,16,17)$.

The roles of PU.1 may differ during the different stages of erythroid differentiation. Proper expression of PU.1 is required for the differentiation of immature erythroid cells. We hypothesized that, at least in certain hematological malignancies, measuring the expression of PU.1 may be useful in predicting the efficacy of low-dose chemotherapies in affecting erythroid differentiation.

\section{Acknowledgements}

This study was supported in part by Grants-in-Aid for Scientific Research (no. 23590687) from the Ministry of Education, Science and Culture of Japan, the Takeda Science Foundation and a foundation from Kitasato University School of Allied Health Sciences (Grant-in-Aid for Research Project, no. 2013-1001). The authors would like to thank Dr Takashi Satoh for helpful discussions.

\section{References}

1. Chen HM, Zhang P, Voso MT, et al: Neutrophils and monocytes express high levels of PU.1 (Spi-1) but not Spi-B. Blood 85: 2918-2928, 1995

2. Rosenbauer F, Wagner K, Kutok JL, et al: Acute myeloid leukemia induced by graded reduction of a lineage-specific transcription factor, PU.1. Nat Genet 36: 624-630, 2004.

3. Pettersson M, Sundstrom C, Nilsson K and Larsson LG: The hematopoietic transcription factor PU.1 is downregulated in human multiple myeloma cell lines. Blood 86: 2747-2753, 1995.

4. Sokalski KM, Li SK, Welch I, Cadieux-Pitre HA, Gruca MR and DeKoter RP: Deletion of genes encoding PU.1 and Spi-B in $\mathrm{B}$ cells impairs differentiation and induces pre-B cell acute lymphoblastic leukemia. Blood 118: 2801-2808, 2011.

5. Kihara-Negishi F, Suzuki M, Yamada T, Sakurai T and Oikawa T: Impaired repressor activity and biological functions of PU.1 in MEL cells induced by mutations in the acetylation motifs within the ETS domain. Biochem Biophys Res Commun 335: 477-484, 2005.

6. Aoyama S, Nakano H, Danbara M, Higashihara M, Harigae H and Takahashi S: The differentiating and apoptotic effects of 2-aza-5'-deoxycytidine are dependent on the PU.1 expression level in PU.1-transgenic K562 cells. Biochem Biophys Res Commun 420: 775-781, 2012.

7. Woessmann W, Zwanzger D and Borkhardt A: ERK signaling pathway is differentially involved in erythroid differentiation of K562 cells depending on time and the inducing agent. Cell Biol Int 28: 403-410, 2004

8. Sztiller-Sikorska M, Jakubowska J, Wozniak M, Stasiak M and Czyz M: A non-apoptotic function of caspase-3 in pharmacologically-induced differentiation of K562 cells. Br J Pharmacol 157: 1451-1462, 2009.

9. Iseki Y, Imoto A, Okazaki T, Harigae $\mathrm{H}$ and Takahashi S: Identification of annexin 1 as a PU.1 target gene in leukemia cells. Leuk Res 33: 1658-1663, 2009.

10. Imoto A, Okada M, Okazaki T, Kitasato H, Harigae $\mathrm{H}$ and Takahashi S: Metallothionein-1 isoforms and vimentin are direct PU.1 downstream target genes in leukemia cells. J Biol Chem 285: 10300-10309, 2010.

11. Iseki Y, Nakahara M, Kubo M, Obata F, Harigae H and Takahashi S: Correlation of PU.1 and signal regulatory protein $\alpha 1$ expression in PU.1 transgenic K562 cells. Int J Mol Med 29: 319-323, 2012.

12. Takahashi S, Harigae H, Kameoka J, Sasaki T and Kaku M: AML1B transcriptional repressor function is impaired by the Flt3 internal tandem duplication. Br J Haematol 130: 428-436, 2005. 
13. Rao G, Rekhtman N, Cheng G, Krasikov T and Skoultchi AI: Deregulated expression of the PU.1 transcription factor blocks murine erythroleukemia cell terminal differentiation. Oncogene 14: 123-131, 1997.

14. Yamada T, Kondoh N, Matsumoto M, Yoshida M, Maekawa A and Oikawa T: Overexpression of PU.1 induces growth and differentiation inhibition and apoptotic cell death in murine erythroleukemia cells. Blood 89: 1383-1393, 1997.

15. Yamada T, Abe M, Higashi T, et al: Lineage switch induced by overexpression of Ets family transcription factor PU.1 in murine erythroleukemia cells. Blood 97: 2300-2307, 2001.

16. Back J, Dierich A, Bronn C, Kastner P and Chan S: PU.1 determines the self-renewal capacity of erythroid progenitor cells. Blood 103: 3615-3623, 2004.
17. Wontakal SN, Guo X, Will B, et al: A large gene network in immature erythroid cells is controlled by the myeloid and B cell transcriptional regulator PU.1. PLoS Genet 7: e1001392, 2011.

18. Takahashi S: Opposing role, depending on the stage, of PU.1 during erythroid differentiation. J Blood Lymph 2: e108, 2012.

19. Donze D, Townes TM and Bieker JJ: Role of erythroid Kruppel-like factor in human gamma- to beta-globin gene switching. J Biol Chem 270: 1955-1959, 1995.

20. Wall L, Destroismaisons N, Delvoye N and Guy LG: CAAT/enhancer-binding proteins are involved in beta-globin gene expression and are differentially expressed in murine erythroleukemia and K562 cells. J Biol Chem 271: 16477-16484, 1996. 